\title{
OUTSOURCING TOWARDS GREATER AGILITY THROUGH INVESTIGATING DECOUPLING POINTS IN LEAGILE SUPPLY CHAINS
}

\author{
Monica Faur $^{1 *}$, and Constantin Bungau ${ }^{1}$ \\ ${ }^{1}$ University of Oradea, Doctoral School of Engineering Science, 1 Universitatii street, Oradea, \\ Romania
}

\begin{abstract}
In today's competitive business environment, with a continuously increasing diversity in customer demand, a high level of supply chain responsiveness is an imperative requisite for companies' survival. As a consequence, enhanced agility is requested for the supply chains. The purpose of this paper is to investigate the determinants that influence the position of the 'decoupling points' along the value chain, as according to the reviewed literature these represent the separation point between leanness and agility in a hybrid supply chain. It has been found that by applying different technical solutions along the chain, including breaking down the complete production process in modular sequences and outsourcing specific ones, considering reshaping the supply chain, the decoupling points' location can be moved, allowing greater agility. The chosen methodology is a case study of a FMCG company, aiming to illustrate how increased agility is achieved by outsourcing labour-intensive and time consuming activities, while shortening the downstream to customer. The selected firm is since several years under Lean and Agile strategies implementation. The study shows that understanding both, material and information decoupling points, certain lean processes can be moved upstream, leveraging more agile processes close to the end customer. This way, supply chains can be redesigned towards increasing market responsiveness.
\end{abstract}

\section{Introduction}

Nowadays, markets are extremely challenging for the manufacturing companies, becoming more demanding or volatile, asking for more customized products, tending to transform into niche-markets, or being totally unpredictable. This difficult environment requires a high coefficient of flexibility on companies' side and also increased adaptability and responsiveness. The market segmentation has dramatically increased over the last few years, evolving to high levels of customized products, demanding companies to rethink or reshape their supply chains in order to survive and get competitive advantage. Studies show that traditional business culture dealing with one big market with mass produced goods is

* Corresponding author: monica.faur@csud.uoradea.ro 
losing market share, unless taking into account various strategies to address niche-markets or handle seasonality, which are linked to customized products and customer-driven supply chains. There are studies revealing that companies engage innovators together with their customers in the product co-creation process [1], aiming to get a final product to best fit to the end - users' requirements. Firms even maintain an open dialogue with their customers and other external stakeholders in order to be proactive regarding new products development. In this view, specific business cultures and special strategies need to be applied and developed to handle today's dynamic environments [2]. Effective supply chain management along with knowledge management are also of great importance to maintain competitive advantage and improve organizational performance. A knowledge-based society determines new approaches of business strategy, knowledge leadership, culture, management content, supply chain design, technology and innovation, which are key enablers for a business to be competitive on the market [3-4].

Lean and Agile strategies seem to be a very common approach that companies are looking in the present to implement, in order to get enhanced efficiency and effectiveness in their supply chains and also to increase responsiveness to customer needs. The present study intends to investigate the factors that influence the position of the 'decoupling points' in leagile supply chains, points that are seen as a borderline between lean and agile practices. The determinants of decoupling points' position will be also analyzed through a case study, to further conclude whether this barrier can be moved along the chain, creating more agile, more flexible and customer oriented value chains.

\section{Leanness and Agility}

According to Drew et al. (2016) both, Lean and Agile management strategies have proven to be successful approaches for businesses, with significant improvements in profits, cashflow, customer satisfaction, market share [5].

Lean management is the provision of maximum customer satisfaction by reducing waste through optimum utilization of resources [6-7]. Lean management also refers to doing more and better things with fewer resources when demand is predictable and the economic environment is stable. Leanness is directly linked with cost reduction, elimination of waste, efficiency, positive organizational culture, in terms of improving processes, discipline and committed leadership to overcome internal and external challenges [8]. Popularized by Womack et al (1990) the concept of lean started to be disputed when it became clear that by implementing lean strategy, a degree of flexibility was lost due to standardization and the supply chains couldn't properly react when facing dynamic markets [9]. Due to these limitations of lean, it was concluded that for certain supply chains a more flexible approach was required, and the concept of agility has been introduced in the literature.

Supply chain agility is the organizational ability to rapidly adapt and promptly respond to dynamic or unpredictable demands. Agile supply chains require provisional sources of supplies and employment, immediately available [10-11]. To accommodate the inherent variations in demand and supply, supply chains need to react and adapt to such changes as they happen, to minimize the disruption and optimize the objectives, such as costs, fulfillment rates, inventory, and so on. An agile supply chain design will have redundancy built into its processes, allowing it to quickly respond to expected changes, maximizing the service levels for fulfilling demand, manufacturing customized products, and providing excellent customer service [12]. An agile supply chain has to be designed to provide the products or services demanded by the customers in dynamic and aggressive markets by means of agility, which refers to the ability to respond quickly to unpredictable market changes [13-14]. From a supply chain perspective, the lean approach aims at reducing the physical costs such as production, distribution and storage costs, whereas 
agility focuses on marketability costs such as obsolescence and stock-out costs, as Gaudenzi and Christopher show in their studies [14-15].

Most of the authors suggest that supply chains need to be lean and agile simultaneously. Successful companies can't afford to have a lean supply chain that is costeffective but not able to react to market changes or an agile chain driven by responsiveness, but simply unsustainable from financial point of view. An agile design of supply chain will manage variability, diversity and unpredictable changes in the demand, lead-time or even customized products, according to customers' expectancy. Some of the products may have a stable demand profile, while others will be more volatile or need to be adapted to customers' need. This means that the most of the supply chains must be redesigned in order to be both lean, to best manage the products with stable demand and agile, to manage others with dynamic demand. The purpose of applying both strategies in a supply chain is to manage the processes as efficiently as possible using a lean and forecast-based structure in the upstream of the chain, while on the other hand focusing on agility and make-to-order approach in the downstream. The goal is to allow the processes to be as flexible as possible [16]. Numerous research publications show that leanness and agility have overall a synergistic effect on the supply chain. Banerjee and Ganjeizadeh, (2017) identified a set of business goals creating synergies as an outcome of lean and agile application in supply chains. These synergies are presented in Figure 1:

- Customer satisfaction (Agility) is achieved by value identification in products (Leanness)

- Increased competitiveness (Agility) is gained by refining flow of material and information (Leanness)

- Systematic planning (Agility) is enhanced by performing the operation when required (Leanness)

- Organization and departments cross-communication (Leanness) is improved by adopting IT and Technology (Agility)

- Suitable utilization of skill (Leanness) is an approach to leverage peopple and information (Agility))

Fig.1. Synergies of leanness and agility on business goals [17]

It's obvious that both paradigms have similarities in respect of the impacts on business goals, despite the fact that they are differently applied to the processes or to the entire value chain. To analyze these synergies, leanness is applied to improve product quality by adopting innovating technology and information technology, which is an agile characteristic, also mentioned in 'The Agile Manifesto'. Embracing a transparent crossfunctional communication, proper to lean practices, by implementing modern IT systems, focusing on individuals and interactions over processes, which represents another core value in the 'Agile Manifesto', will lead to extra flexibility, market adaptability and overall increased customer satisfaction.

Lean and Agile are different approaches, having also clearly identified boundaries. The distinction between the two paradigms has been empirically tested by Hallgreen and Olhager (2009). In terms of drivers and performance outcomes, they found that lean is associated with cost leadership and cost performance, while agile is linked to product differentiation and flexibility performance. [18]

\section{Decoupling Points in the Context of Leagility}

The combination of the two strategies, lean and agile, is termed in the literature as leagility. The concept of leagility was proposed in order to build a relationship between agility, lowcost production and effective supply chain [14]. The common goal of the lean and agile supply chain strategies is to meet the customers' demands at the lowest cost possible [19].

The boundaries between Lean and Agile are delineated through a strategic point called 'decoupling point' (DP). The term has been introduced in the literature by Hoekstra and Romme (1992) and has been defined as 'the point in the product flow to which the 
customer's order penetrates' [20,21]. The decoupling point separates the part of the supply chain oriented towards customer, where agile practices are applied, from the part of the supply chain based on forecast, which is supplier oriented and where lean practices are implemented [20]. Mason-Jones and Towill (1999) suggest that there are at least two axes within the supply chain, one representing the material flow and the other one the information flow [22]. Both of them have their specific decoupling points, therefore called 'material decoupling point' and 'information decoupling point'. The 'material decoupling point' overlaps the 'decoupling point' proposed by Hoekstra and Romme (1992). MasonJones and Towill (1999) defined the 'information decoupling point' as 'the point in the information pipeline to which the marketplace order data penetrates without modification' [22]. Olhager (2012) states that the 'feedback of market information does not necessarily stop at the material flow DP, but can be forwarded upstream to provide advanced planning information' [23]. Actually, 'the information DP moves from the customer towards the supplier and must be positioned as close as possible to the beginning of the supply chain, while the material DP is the closest possible point to the end-user within a supply chain. Still in practice, the material and the information DPs most often coincide'[23].

The DP is also 'the point where strategic stock is often held as a buffer between fluctuating customer orders and/or product variety and smooth production output' [21]. Olhager (2010) states that DP is the last point where the inventory is maintained [24]. It is the point that distinguishes manufacturing within a product stream based on forecasts from manufacturing based on customer orders [25]. In other words, DP distinguishes the customer-driven manufacturing from forecast-driven management [26]. The DP is also described in the literature as 'the point where the product is customized', where differentiation starts, actually the point until which the production is 'postponed'. The postponement strategy refers to delaying the final form of a product or the final assembly process as long as possible in a value chain, until the customer orders are received [27-28]. While all the activities before DP in the chain are standard activities, those activities after DP are customized and carried out according to the specific customer order [29]. In order to apply the postponement strategy, the supply chain has to be designed to support that choice. Modularity, namely 'modular product design' and 'modular process design', proposed by Feitzinger and Lee (1997), [30] can be used as a tool to reshape the supply chain. The first term refers to dividing the design of the final product into several components that can be manufactured separately or even in parallel, having a standardized component that can be used within different products. The modular process design refers to breaking down the complete production process into several separate sub-processes. The idea of independent processes is to have the possibility to re-sequence them, have them performing in parallel, in-house, or outsource them, reducing the manufacturing time and shorten the downstream to customer. Postponement strategies contribute to leanness as well as to agility. On the one hand, by delaying product differentiation, the supply chain produces standard semi-finished products as long as possible. Product differentiation occurs at the material decoupling point, where the generic inventory is regarded as strategic stock and only differentiated processes cause delay.

The existing leagile literature is quite poor when it comes to the determinants of the precise location of the DP. Some of the influencing factors are reflected below, provided that most of the authors refer to DP as to the material DP. So, the position of the material DP depends on:

- the longest lead-time the end-user is prepared to tolerate [21-22]

- the product variety and variability in demand, including product customizing and seasonality; an increase in product variety and fluctuating volume of demand would push the material DP to move upstream, allowing the supply chain to be more agile ; in 
contrast, a more stable business environment with lower product variety and stable demand would move the DP downstream, making the supply chain leaner [31].

- the capital investment along the supply chain, referring to the levels of fixed investment in the equipment used at different processing stages; high capital investment processes in the value chain provide barriers to the free movement of the DP, but that can also provide an insight about where the DP can most profitably be located [32]

- the postponement strategy; Naylor et al. (1999) showed that a 'postponement' strategy contributes to moving the material decoupling point closer to the endcustomer, thereby increasing both the efficiency and the responsiveness of the supply chain [21]. Childerhouse and Towill (2000) define postponement as 'the application of the material DP before the point of product differentiation' [33].

- Product and processes modularity; modularity enables a company to produce standard semi-finished products under leanness approach, improving efficiency and delay assembling the components that differentiate the products as long as possible along the chain, placing these processes closer to the end-customer. This will significantly reduce the lead-time from order placement to product delivery, increasing the responsiveness of the supply chain.

Based on the literature research, Aktan and Akyus (2017) identified more criteria that influence the material DP location, and structured them as market related, product related and process related [34]. The criteria are summarized in Figure 2.
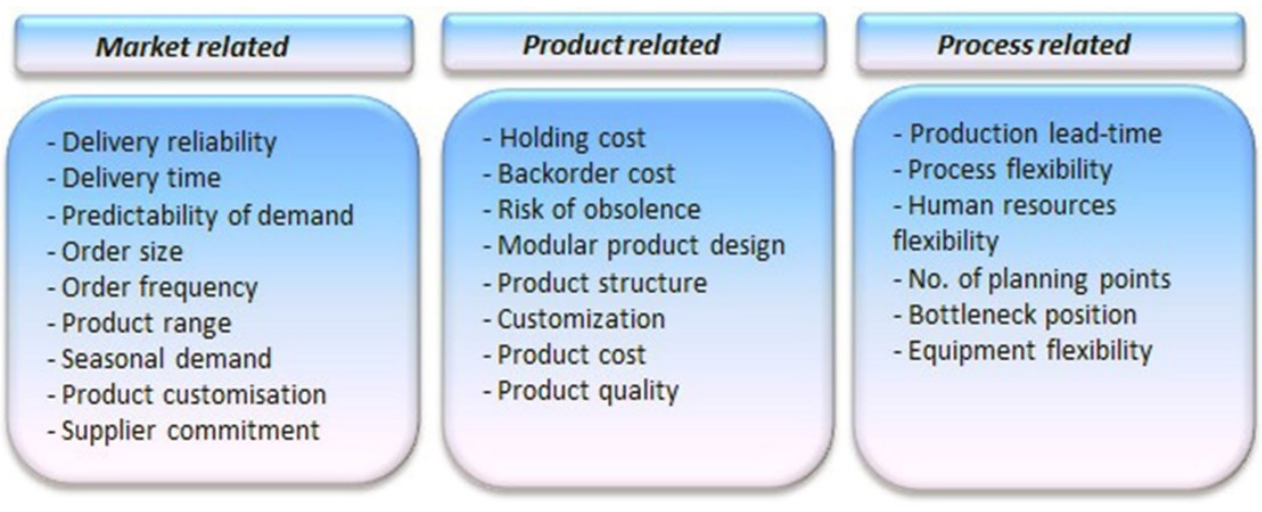

Fig. 2. Cryteria influencing the DP position. Source [34]

Most of the determinants of the DP position, earlier identified in the present paper, are among the criteria summarized by Aktan and Akyus, but there are also other factors like supplier commitment or bottleneck position, mentioned in Figure 2, that need to be given attention, as they could have an impact on the DP location.

Different structures of supply chains have also various positions of DP, referring hereby to the material DP. As shown in Figure 3, structures like 'engineer to order' (ETO) or 'make to order' (MTO) place the DP upstream the chain, closer to the raw material supplier, 'assembly to order' (ATO) structures have the DP located at the assembly stage, where the semi-finished inventory is held, while in structures like 'make to stock'(MTS) the DP is positioned more closer to the customer, before product differentiation stage [18, 21]. 


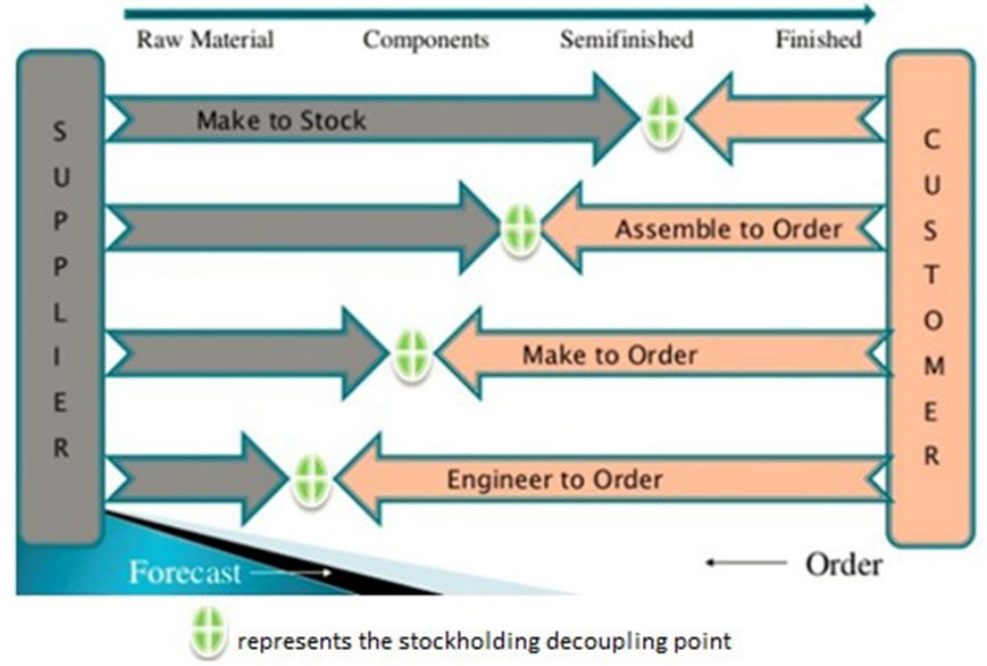

Fig.3. Different positions of DP. Source [35]

At the end of the above mentioned range, close to the end-user, there is to mention 'ship to stock' (STS) chain structure as well, with the DP at the distributor or at the retailer. MTS/STS approaches can offer products with short lead-times, usually standard products, therefore forecast accuracy in these cases is of the essence to minimize the risk of stockouts and overproduction. On the other hand, within MTO/ETO chain designs, the product is tailored from early stages according to customer requirements, thereby carrying a low risk of stock obsolence and enhancing responsiveness.

A disadvantage to be mentioned here is that customers might need to accept longer leadtimes. The most equitable supply chain shape which best fits to leagile strategy seems to be ATO, where the the risk of stock obsolence is balanced with the requirement of shorter lead-times [32]. Nieuwenhuis and Katsifou (2015) argue in their study that a new understanding of the determinants of the DP location along a supply chain can be used in order to bring about a radical shift in economies of scale in car production, theory which was illustrated by the case study of Morgan Motor Company [32].

The related literature shows that there are substantial differences between operations and activities upstream the DP versus those downstream the DP. The key aspects are summarized in Figure 4.

\begin{tabular}{|lll|}
\hline Features & MTS and upstream the DP & MTO and downstream the DP \\
\hline * Product characteristics & $\begin{array}{c}\text { Standard components, high volumes, } \\
\text { predictable demand } \\
\text { Price }\end{array}$ & $\begin{array}{c}\text { Customised, high variety, wide range, } \\
\text { unpredictabledemand }\end{array}$ \\
* Orderwinner & Quality, delivery reliability & $\begin{array}{l}\text { Delivery speed, flexibility } \\
\text { Quality, delivery reliability }\end{array}$ \\
* Qualifiers & Physicallyefficient & Market responsive \\
* Supply chain design & Lean & Agile \\
* Lean versus agile & Low cost manufacturing, & Manufacture to customer specification, \\
& maintain high stock availability at DP & achieve short and reliable lead-time \\
$*$ Key properties & Productivity & Flexibility \\
* Improvement priorities & Cost reduction & \\
& & \\
& & \\
& & \\
& &
\end{tabular}

Fig.4. Distinguishing features of operations and activities upstream versus downstream the DP [23] 
The strategic positioning of the DP means that the best of Leanness and Agility can be achieved by minimizing costs and timing via the application of lean principles upstream and satisfying unpredictable market conditions via agile principles downstream.

As main actions, costs must be reduced, lead times have to be compressed, material flows optimized and synchronized, information flows need to be made transparent across all the functions, in a nutshell both, design and strategy of the supply chain have to be improved [36].

\section{Case study: Outsourcing Repacking Operations in a FMCG Manufacturing Company}

The chosen methodology for the present research is a case study concerning a fast moving consuming goods (FMCG) manufacturing company, with a medium to large size facility.

The reasons why this company case was selected to illustrate the research scope, namely the determinants of the DP position and their influence on the degree of agility of a supply chain, are presented below:

- The company has a leagile supply chain, being under lean strategy implementation since several years, while recently focusing as well on agility improvement.

- The products released on the market are both standard products and diversified products, the last-mentioned ones being obtained through repacking activities, taking place at the end of the manufacturing stage, using a postponement approach. The supply chain structure is a combination of MTS, for the generic products and ATO, for the customized products.

- The customized products flow is not a continue one all over the year, being linked to seasonality, promotion projects and special events, or niche markets.

- An inventory of standard products is held at a point identified as DP1, for the generic products and another buffer inventory is held at DP2, consisting in customized, differentiated products, obtained through repacking activities.

- The customized goods, in terms of how they are presented, packed, dimensioned, personalized, fit best to customers' requirements, the entire operation being closely under Marketing department's surveillance, through different projects depending on seasonality, niche markets and promotions.

- Due to its discontinuous character, the repacking activity is carried out through a leasing employees approach.

- The repacking operations are mostly handled manually, with a low investment in repacking equipment.

- The repacking section can be considered as a modular process of the complete manufacturing process of customized products.

- Customized products cost is subject to reduction, considering the manual work and all the no value-adding activities derived from the leasing employees approach.

The simplified supply chain of the company is presented in Figure 5. 


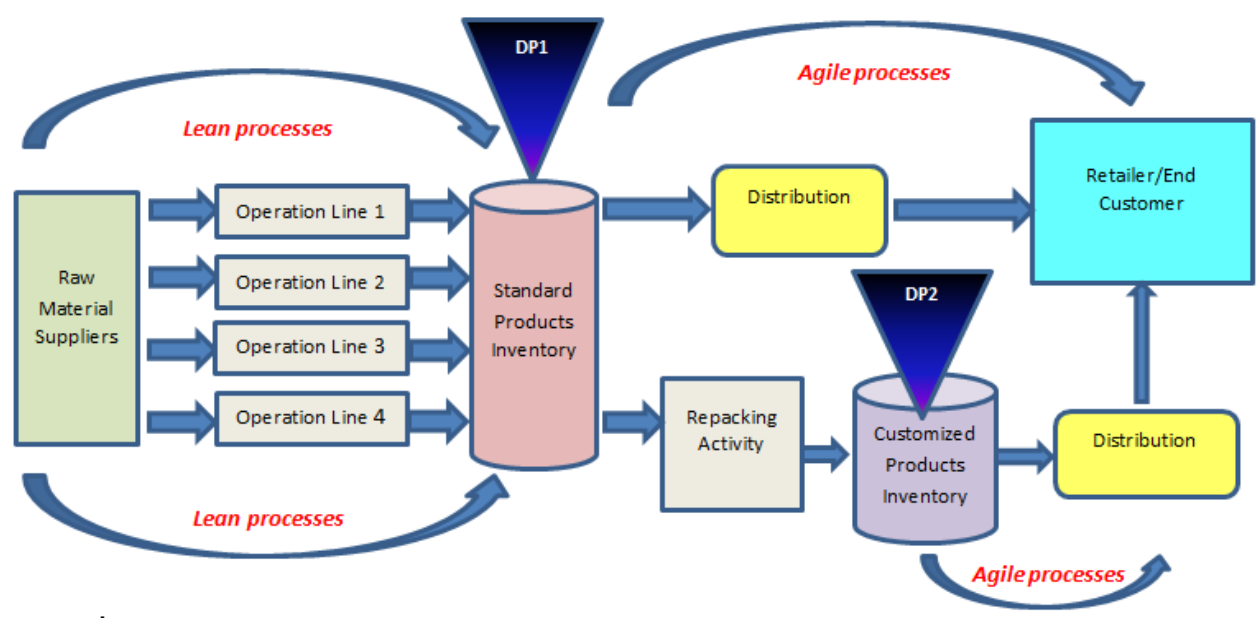

Fig.5. The focal company's simplified supply chain

It is important to notice that the focal company resonates with most of the determinants that have been identified in the previous section of the paper, as to impact the position of the material DP. The value chain is a divergent one, splitting in two separate flows from the point of standard products inventory, thereby two DP can be identified: DP1 and DP2. The repacking activity is not under a lean strategy, as technology used in this area is poor and leasing employeest approach is quite hard to control due to personnel changeability, employees' lack of responsibility and lack of motivation. Actually, the company faced high rates of rejected packages, concerned degrees of poor quality regarding customized goods, overtime costs due to both demand fluctuations and the rejected packages that had to be repacked again...etc. As a result, the stakeholders decided that the repacking operation was no longer efficient in the way it functioned at that time, so a new solution had to be proposed and adopted, as replacement. The options were either investing in a modern repacking line, with new technology, or outsourcing the repacking sequence of the value chain to reliable operators. Outsourcing is understood as 'the act of obtaining semi-finished products, finished products or services from an outside company if these activities were traditionally performed internally [37]. While firms outsource manufacturing activities, the focus is on the impact on volume flexibility, which is a main objective usually targeted from outsourcing [38]. However, when deciding whether to outsource, decision makers show to rely on cost comparisons [39], rather than on the degree of flexibility that can be achieved. Accordingly, the outsourcing condition in the presented case was:

Cost of outsourcing < Cost of in-house repacking, or

Cost of outsourcing for 2 years < Cost of investment in modern repacking technology,

depending on the evaluation conducted by the project team and validated by the top management.

The present study is based on the first author's direct involvement in the project, as a member of the Procurement function of the focal company, over the project development and implementation time. Both, investing in new technology and outsourcing proposals have been included in the project. The project team, consisting of representatives of Procurement, Marketing, Repacking, Manufacturing and Finance ensured a rich understanding of the managerial priorities such as the cost of capital investment, the need of flexibility, the total cost of outsourcing, including logistic costs and both options have been correctly evaluated. Both proposals were moving DP2 upstream the chain, in the leanness 
zone, providing also a lean repacking operation. Procurement team collected the specifications from the interested functions, investigated the market and launched the bidding process based on advanced strategic sourcing techniques [40], in order to get competitive offers from reliable companies for both, advanced repacking equipment and services. Based on the data provided by Procurement a deep analysis has been performed by the project team with the involvement of all interested stakeholders and the proposals have been presented to the top management. The cost of outsourcing was almost equal to the cost of in-house repacking and the cost of a modern repacking line was higher than the cost of outsourcing activities for two years, based on former volumes and in-house repacking experience. The outsourcing solution has been chosen to reconfigure the chain, due to lower cost versus capital investment and other competitive advantages like shorter lead-time, increased volume per order and overall higher flexibility in dealing with fluctuating demand and seasonality of customized products. It has been decided to conclude agreements with two of the top suppliers with highest score in the evaluation performed by the project team within the bidding process. The reason behind this decision was to have a back-up and to also have the possibility to produce several orders in the same time, to get more flexibility and responsiveness in case of unpredictable demands. The transition from in-house to outsourced repacking was smooth, using both variants in parallel at the beginning of outsourcing implementation and easily removing the leasing employees' approach within the time. Suppliers' commitment and cross-functional cooperation and communication were of the essence. Through outsourcing implementation, the following results have been achieved:

- Increased flexibility and responsiveness due to the capacity of the chosen companies to absorb or balance customized products fluctuating orders, or unpredictable demand;

- Volume per order increased by an average of $18 \%$ per month, as shown in Figure 6, due to transition to partially automatized processes;

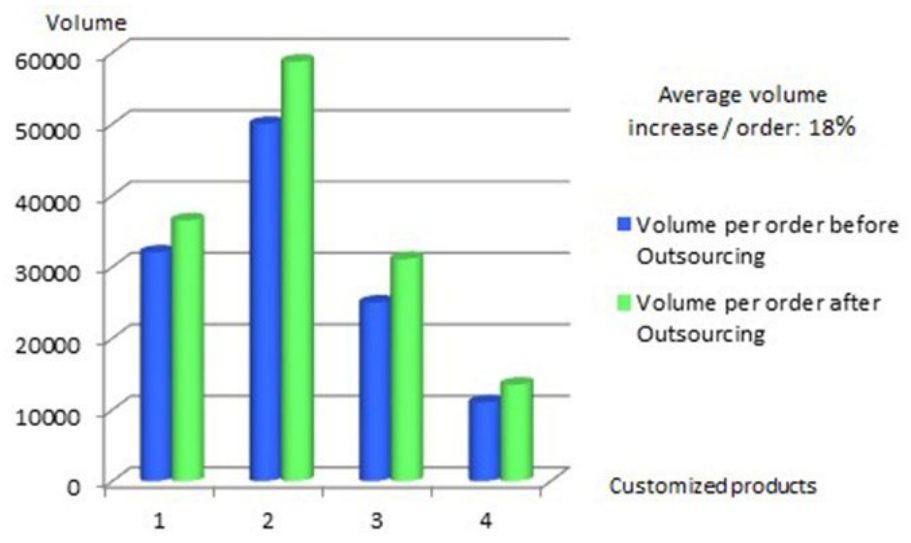

Fig.6. Increase of volume per order for different customized products, before and after outsourcing

- $\quad$ Improved product quality due to advanced technologies used and specialized personnel at the outsourcing companies;

- Lead times from orders to delivery to the end-customers have been compressed by about $24 \%$ per month, as shown in Figure 7 ; this means that the products were delivered to the customers with an average of 2.75 days earlier than in case of inhouse repacking, when the average delivery time was 11.25 days; 


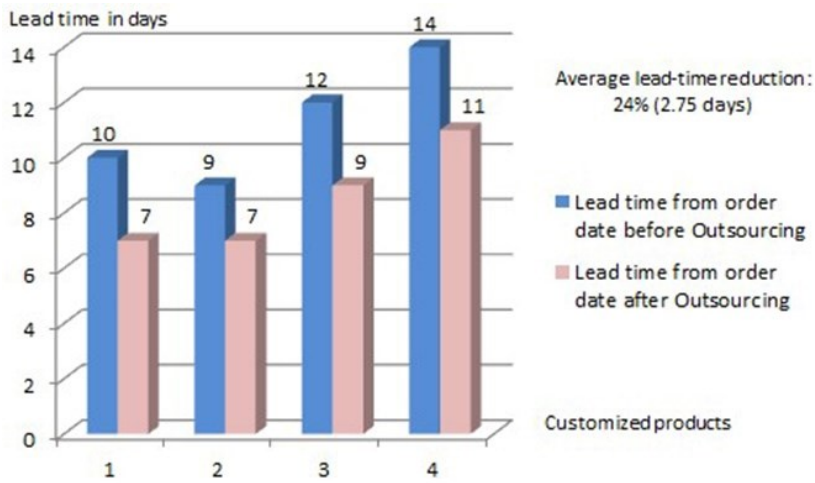

Fig.7. Lead time compression per order, for different customized products, before and after outsourcing

- $\quad$ Enhanced efficiency, by moving activities in a lean zone, at suppliers' facilities;

- Use of the created spare capacities for other activities like storage, or another production line

- A fee/package was negotiated for the customized products, for each project, instead of managing high complexity in administrating repacking activity by leasing employees approach; in this respect, outsourcing represents also an important movement from complexity towards simplicity.

- Mutual agreements have been concluded with the repacking service providers (two contracts, in order to manage risk and create competition among suppliers)

- Having two suppliers for outsourced services, two or many orders for different products could be produced in parallel, as presented in Figure 8:

Supplier $1 / 2$
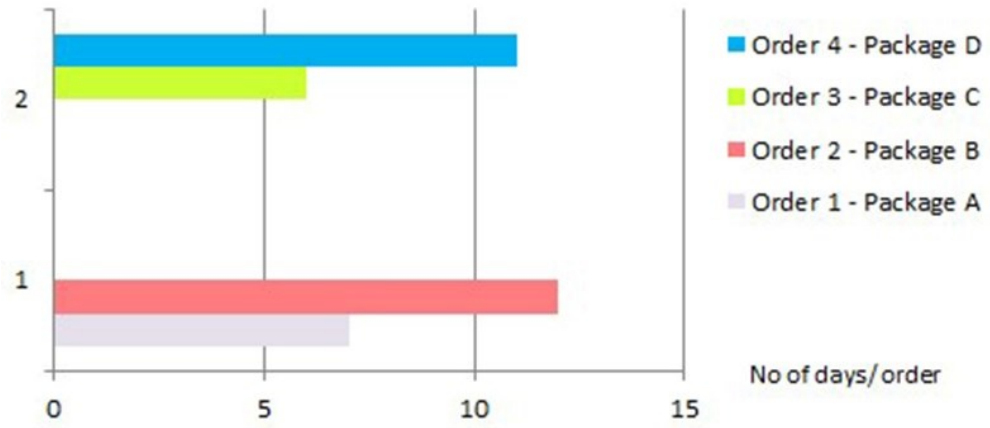

No of days/order

Fig.8. Simultaneous repacking orders at two suppliers after outsourcing

- $\quad$ Product cost reduction has been gained by negotiating the fee per package for each project and by eliminating waste and overtime costs caused by the leasing employees case; $8 \%$ savings have been achieved versus in-house packaging cost, for the first ongoing projects;

- Supply chain structure has been redesigned, with streamline processes; DP2 was moved upstream the chain, at the point of DP1, leveraging more agility.

The new shape of the supply chain upon outsourcing implementation is reflected in Fig. 9: 


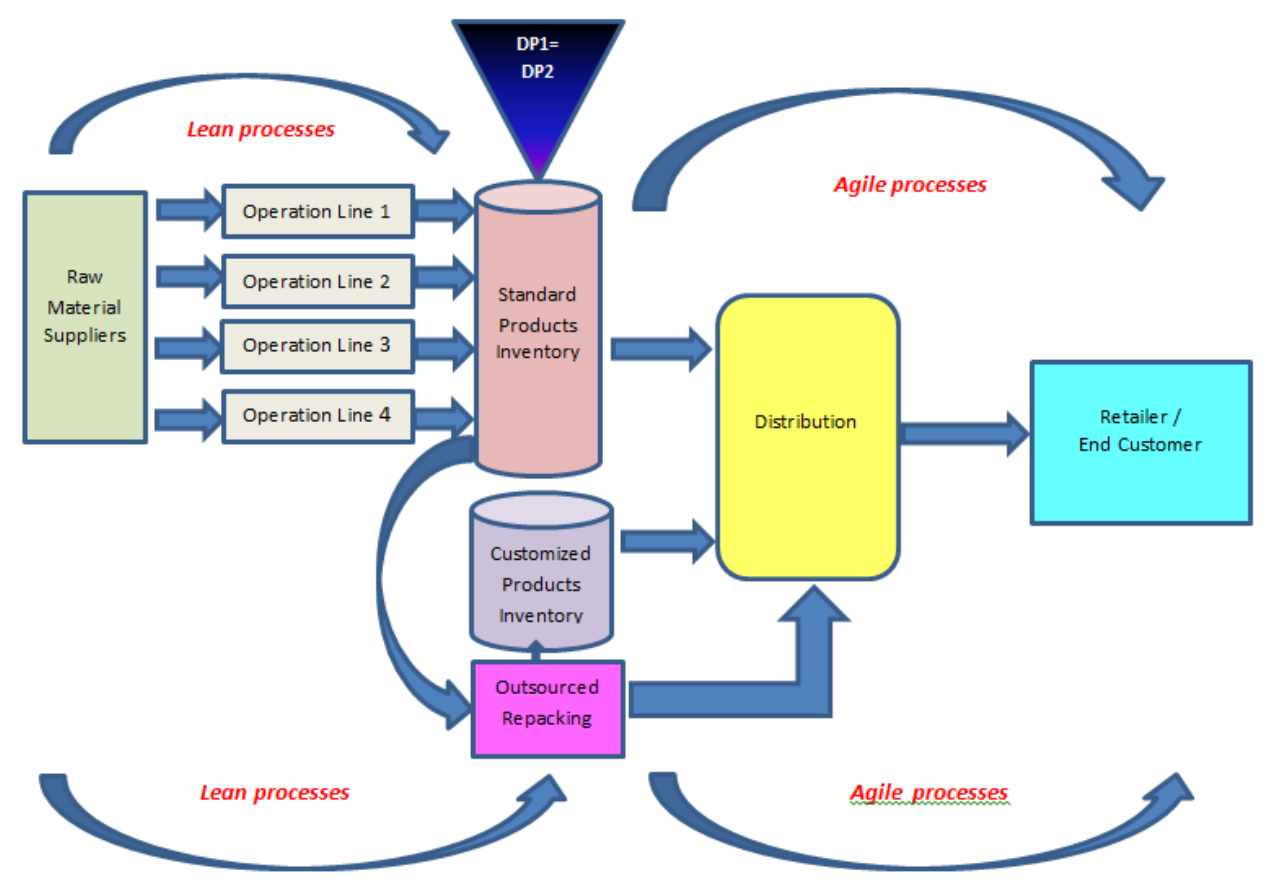

Fig.9. The focal company's simplified supply chain, upon outsourcing implementation

\section{Conclusions}

Outsourcing is a useful tool and an important mechanism for improving manufacturing supply chains, being associated with cost reductions, focus on core competencies and specialized process knowledge, enabling capacity shortages and increasing flexibility.

By investigating the DPs in a leagile supply chain and the factors that influence their positions, it has been found that they can be moved along the chain by applying various strategies or technical solutions to the manufacturing stages, thereby allowing different degrees of agility or leanness.

The constraints to the free movement of the DPs are mainly given by the balance between capital investment and labour, by the longest lead-time the end-user is prepared to tolerate and the product and processes modularity. A supply chain with modular processes is easier to architect or re-arrange towards achieving greater flexibility.

The business case study validates the solution of adopting outsourcing strategy when dealing with labor-intensive processes, allowing the suppliers to work under lean practices, while favoring more agile processes near the end-customer. In the authors view, even though significant efforts are needed to break down a production flow in several segments, sometimes it is worth to do it, in order for the supply chain to become more responsive.

The decision for outsourcing not only has to take in account the total cost of the process, as a short term action, but it also has to be viewed as a long term change, focusing on enhanced responsiveness to the more challenging market conditions. Moreover, in case of outsourcing, supplier's commitment, cross-functional cooperation and communication are extremely important.

Further research directions on the presented topic could focus on the triggers of the decision-making process, including an extended analysis of the outsourcing costs compared to in-house activity costs and capital investment alternative. Another research option to be 
considered is related to the risks associated with outsourcing, as by applying this practice the demand risks are somehow transferred from the primary parties in supply chains to the service providers. Some new risks are introduced by the outsourcing contracts, therefore they need to be carefully concluded, with the help of experts, and then continuously monitored.

\section{References}

1. S. Avasilcai, G.Rusu, Co-creation value through customers' proactive engagement: A case study of Heineken (B), Fascicle of Manag and Techn. Eng., ISSN 1583-069, 24, 14 (2015)

2. I. Abrudan, D. Cândea, Manual de Inginerie Economică. Ingineria şi managementul sistemelor de productie, Editura Dacia, Cluj-Napoca, ISBN 973-35-1588-4 837 (2002)

3. M.S., Sangari, R. Hosnavi, M.R. Zahedi, The impact of knowledge management processes on supply chain performance, Int. J. Logist. Manag, 26, 3, pp.603-626 (2015)

4. A. Draghici, Adaptive technologies and business integration: Social, managerial and organizational dimensions, IGI Global, pp.211-243 (2007)

5. J. Drew, B. McCallum, S. Roggenhofer, Journey to lean: making operational change stick, Springer (2016)

6. J.P. Womack, D.T. Jones, Lean thinking: banish waste and create wealth in your corporation: Free Press, ISBN13: 9780743249270 (2003)

7. A. Cozzolino, S. Rossi, A. Conforti, Agile and lean principles in the humanitarian supply chain: The case of the United Nations World Food Programme. J. of Humanitarian Logist. and SC Manag., 2, 1, pp.16-33 (2012) http://doi.org/10.1108/20426741211225984

8. V.C. Lassiter, The Role of Process Improvement in the Nonprofit Organization, (Master of Science in Organizational Dynamics), University of Pennsylvania Philadelphia (2007)

9. B. Walker, D. Salt, Resilience Thinking; Sustaining Ecosystems and People in a Changing World, Island Press, Washington (2006)

10. M. Christopher, D.R. Towill, The supply chain strategy conundrum: to be lean or agile or to be lean and agile? Int. J. Logist. Manag. 5, 3, pp.299-309 (2002)

11. L. Lapide, MIT's SC2020 project: The essence of excellence. S.C. Manag. Rev., 10, 3, (2006)

12. https://www.supplychainmusings.com/2010/10/agile-as-supply-chain-strategy.html, accessed 20.01 .2019

13. S.H. Huang, M. Uppal, M. Shi, J. A product driven approach to manufacturing supply chain selection, Supply Chain Management: An Int. J. 7, 4, pp.189-199 (2002)

14. B. Gaudenzi, and M. Christopher, Achieving supply chain 'leagility', through a project management orientation, Int. J. of Log.: Research and Applications, 19, 1, pp.3-18 (2016)

15. M. Christopher \& D. Towill, An Integrated Model for the Design of Agile Supply Chains, Int. J. Phys. Distrib. \& Log. Manag., 31, 4 (2001)

16. D.P. Van Donk, and R. Van Doorne, The impact of the customer order decoupling point on type and level of supply chain integration, Int. J. Prod. Research, 54, 9, pp.2572-2584 (2016)

17. A. Banerjee, F. Ganjeizadeh, Modeling a Leagility Index for Supply Chain Sustenance, Procedia Manufacturing 11, pp.996-1003 (2017)

18. M. Hallgren, J. Olhager, Lean and agile manufacturing: external and internal drivers and performance outcomes, Int. J. of Op. \& Prod. Manag., 29, 10, pp.976-999 (2009)

19. F. Qi, X. Xuejun, G. Zhiyong, Research on lean, agile and leagile supply chain, IEEE Int. Conf. on Wireless Communications, Networking \& Mob. Computing, Shangai, pp.4902-4905 (2007)

20. S. Hoekstra, J. Romme, Integrated Logistics Structures: Developing Customer Oriented Goods Flow, McGraw-Hill, London (1992)

21. J.B. Naylor, M. Naim, D. Berry, Leagility: integrating the lean and agile manufacturing paradigms in the total supply chain, Int. J. Prod. Econ. 62 (1-2), pp.107-118 (1999)

22. R. Mason-Jones, D.R. Towill, Using the information decoupling point to improve supply chain performance, Int. J. Logist. Manag. 10, 2, pp.13-26 (1999)

23. J. Olhager, The role of decoupling points in value chain management. In Modelling value. 37-47. Physica-Verlag HD, (2012) https://doi.org/10.1007/978-3-7908-2747-7 2 
24. J. Olhager, The role of the customer order decoupling point in production and supply chain management, Computers in Industry, 61, 9, pp.863-868 (2010)

25. J. Wikner, M. Rudberg, Integrating production and engineering perspectives on the customer order decoupling point, Int. J. Op. \& Prod. Manag., 25, 7, pp.623-641 (2005)

26. T.J. Van Kampen, D.P. Van Donk, When is tt time to revise your SKU classification: setting and resetting the decoupling point in a dairy company, Prod. Plann. \& Control, 25, 16, pp.13381350 (2014)

27. M. Christopher, The Agile Supply Chain: Competing in Volatile Markets. Ind. Mark. Man., 29, 1, 37-44, (2000) https://doi.org/10.1016/S0019-8501(99)00110-8

28. M. Christopher, D.R. Towill, Don't lean too far - evidence from the first decade. Int. J. Agile Syst. Manag. 2 (4), pp.406-424 (2007)

29. K.A. Ferreira, R.L. Alcantara-Chicarelli, Postponement adoption in manufacturers of tomatoderived products, British Food J., 118, 2, pp.362-378 (2016)

30. E. Feitzinger, H.L. Lee, Mass customization at Hewlett-Packard: the power of postponement, Harv. Bus. Rev. 75 (1), pp.116-121 (1997)

31. R.. Krishnamurthy, C.A. Yauch, Leagile manufacturing: A proposed corporate infrastructure, Int. J. of Op. and Prod. Manag., 27, 6, pp.588-604 (2007) https://doi.org/10.1108/01443570710750277

32. P. Nieuwenhuis, E. Katsifou, More sustainable automotive production through understanding decoupling points in leagile manufacturing. J. of Cleaner Prod., 95, 232-241, (2015) https://www.sciencedirect.com/science/article/pii/S0959652615002103

33. P. Childerhouse, D. Towill, Engineering supply chains to match customer requirements', Logistics Information Manag., 13, 6, pp.337-345 (2000)

34. H.E. Aktan, and G. Akyuz, Positioning the decoupling point along a supply chain: a case study, Int. J. Productivity and Quality Management, 22, 3, pp.309-339 (2017)

35. https://www.slideshare.net/PratikKelkar/customer-order-decoupling-point-42762502, accessed 20.01.2019

36. M. Faur, C. Bungau, Supply Chain 'Leagility' through Adopting Consignment Stock Strategy in Manufacturing Companies, RMEE - 6th International Management Conference (2018)

37. A. Dolgui, J.-M. Proth, Outsourcing: definitions and analysis. Int. J. of Prod. Research, 51, 2324, pp.6769-6777 (2013)

38. M. Scherrer-Rathje, P. Deflorin, G. Anand, Manufacturing flexibility through outsourcing: effects of contingencies, Int. J.of Op. \& Prod. Manag., 34, 9, 1210-1242 (2014)

39. M. Gylling, J. Heikkilä, K. Jussila, M. Saarinen, Making decisions on offshore outsourcing and backshoring: A case study in the bicycle industry. Int. J. of Prod. Ec., 162, 92100 (2015) http://dx.doi.org/10.1016/j.ijpe.2015.01.006

40. M. Faur, Perspectives in Developing the Suppliers' Strategy within Procurement Processes, RMEE, 17, 1, pp. 99-111 (2018) 